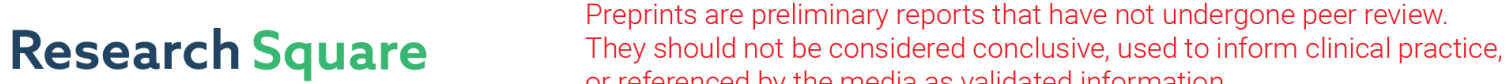 or referenced by the media as validated information. \\ Effect of Ultrasonic Compound Cutting on the Microstructure and Properties of Formed Chip
}

\section{Haimeng Sun}

School of Mechanical and Power Engineering, Henan Polytechnic University

\section{Feng Jiao}

School of Mechanical and Power Engineering, Henan Polytechnic University

Ying Niu ( $\nabla$ niuying@hpu.edu.cn )

Henan Polytechnic University

\section{Zhuangfei Wang}

School of Mechanical and Power Engineering, Henan Polytechnic University

\section{Research Article}

Keywords: pure copper, ultrasonic compound cutting, 3D FEM equivalent model, microstructure, mechanical properties

Posted Date: August 23rd, 2021

DOI: https://doi.org/10.21203/rs.3.rs-821808/v1

License: (c) (1) This work is licensed under a Creative Commons Attribution 4.0 International License. Read Full License

Version of Record: A version of this preprint was published at The International Journal of Advanced Manufacturing Technology on April 2nd, 2022. See the published version at https://doi.org/10.1007/s00170-022-09147-7. 


\title{
Effect of ultrasonic compound cutting on the microstructure and properties of formed chip
}

\author{
Haimeng Sun ${ }^{1}$. Feng Jiao ${ }^{1}$. Ying Niu ${ }^{1}$. Zhuangfei Wang ${ }^{1}$.
}

\begin{abstract}
Sever plastic deformation (SPD) with high strain rate can increase the material dislocation density, reduce the grain size and improve the mechanical properties. In this paper, ultrasonic compound cutting (UCC) was proposed to improve the efficiency of preparing ultra-fine grained (UFG) pure copper by sever plastic deformation methods. The motion characteristics and strain rate model of UCC were analyzed, and it was concluded that ultrasonic vibration can increase the strain rate in the primary shear zone. According to the $3 \mathrm{D}$ FEM equivalent model of UCC, the UCC and traditional compound cutting (TCC) were compared and analyzed from the perspective of strain rate. The simulation results show that ultrasonic vibration can significantly increase the strain rate of chip. The microstructure and mechanical properties of pure copper chip were studied by using a self-developed machining device. The experiment results show that the grain refinement, dislocation density and micro-hardness of pure copper chip were significantly improved in UCC. When the ultrasonic amplitude is $3 \mu \mathrm{m}$, the UCC chip grains are about $2.66 \mu \mathrm{m}$ and the hardness reaches $124 \mathrm{HV}$, which is about $8 \%$ higher than the hardness of TCC chip. The findings of this research provide an important reference for machining UFG pure copper with enhanced mechanical properties.
\end{abstract}

Keywords: pure copper; ultrasonic compound cutting; 3D FEM equivalent model; microstructure; mechanical properties

\section{Introduction}

Micro-electro-mechanical systems (MEMS) play an important role in modern industry and are widely used in biomedicine, electronic communication and aerospace fields. The rapid rise of MEMS has driven the current industry towards miniaturization and miniaturization [1]. In MEMS, if traditional materials are used to produce micro-parts, the average grain size is usually above 10 microns, which is the same as the characteristic size of most micro-parts. This will cause size effect and reduce the dimensional accuracy and service life of parts [2]. Ultra-fine grained (UFG) materials have attracted widespread attention for their excellent properties such as high strength, high toughness, lower ductile-brittle transition temperature, high strain rate and low temperature superplasticity, etc [3]. If UFG materials are applied to micro-parts, it will improve the overall performance of MEMS. Pure copper is widely used in MEMS as an important basic material and functional material. At the same time, UFG pure copper has high strength, ductility, electrical and thermal conductivity and fatigue properties, etc $[4,5]$. Therefore, the preparation of UFG pure copper and the study of microstructure and properties have become one of the current research hotspots.

Severe plastic deformation (SPD) can effectively refine the internal structure of the material by applying large shear strain to produce UFG materials with large angular grain boundaries, and the grain size can be refined to several hundred nanometers. SPD methods including equal channel angular pressing (ECAP) [6], high pressure torsion (HPT) [7], accumulative roll bonding (ARB) [8], and cyclic extrusion compression (CEC) [9] are therefore employed to produce UFG materials. SPD can significantly increase the density of metals and alloys, eliminate internal defects in materials, and make it difficult to cause pores and pollution in machining. However, SPD has Ying Niu (corresponding author)

niuying@hpu.edu.cn

Haimeng Sun

1605255416@qq.com

1 School of Mechanical and Power Engineering, Henan Polytechnic

University, Jiaozuo 454000, Henan, China 
many limitations. Firstly, due to the limitations of forming equipment, the strain rate of SPD machining is very small $\left(<10^{2} \mathrm{~s}^{-1}\right)$ and the temperature in deformation zone is also very low, so SPD is difficult to deform medium and high-strength alloys. Secondly, SPD needs multiple machining to produce large strain, which will lead to uncertainty in the control of deformation parameters (e.g., strain, strain rate) and deformation paths [10].

Among these SPD techniques, large strain extrusion machining (LSEM) [11] is an attractive method for preparing UFG materials. It not only imposes large shear strain on materials in a single pass, but also has unique advantages in controlling chip forming and continuous production, which is easier to be further machined into MEMS micro-parts.

At present, the demand for high-performance industrial materials is growing rapidly, so scholars have started to study ultrasonic vibration assisted technology to prepare UFG materials. Ultrasonic vibration machining can improve the traditional manufacturing processes, and make significant changes in mechanical properties, micro morphology, surface integrity and fatigue properties of materials [12, 13]. Ahmadi et al. [14] designed an ultrasonic assisted ECAP system, and the punch can be excited by ultrasonic vibration. The results showed that the grains of pure aluminum samples were refined to $45 \mu \mathrm{m}$ in ECAP machining, and when the amplitude was $2.5 \mu \mathrm{m}$ and $5 \mu \mathrm{m}$, the material grains were refined to $28.2 \mu \mathrm{m}$ and $22 \mu \mathrm{m}$, respectively. It was proved that ultrasonic vibration can significantly improve the grain refinement of pure aluminum. Zhang et al. [15] used shot peening and ultrasonic shot peening to machine 7075-T651 aluminum alloy. The results showed that the surface roughness in ultrasonic shot peening was reduced by $35.5 \%$, and the surface hardness was increased by about $31.9 \%$. Cheng et al. [16] carried out an ultrasonic rolling experiment with 45 steel. When the amplitude was increased from $0 \mu \mathrm{m}$ to $6 \mu \mathrm{m}$, the depth of structure refinement increased from $17 \mu \mathrm{m}$ to $53.5 \mu \mathrm{m}$. The results indicate that ultrasonic vibration rolling can effectively refine the internal structure of 45 steel. A large number of literatures show that ultrasonic vibration can increase the grain refinement and surface hardness of materials, and the combination of ultrasonic vibration and SPD can achieve better results than traditional machining methods [17, 18].

In this paper, a new ultrasonic compound cutting (UCC) method was proposed on the basis of LSEM. According to the motion characteristics and strain rate model of UCC, the effect of ultrasonic vibration on the strain rate in the primary shear zone was analyzed. The 3D FEM equivalent model of UCC was established, and the differences between traditional compound cutting (TCC) and UCC were compared and analyzed from the viewpoint of strain rate. The microstructure features and mechanical properties were characterized by employing optical microscopy (OM), scanning electron microscope (SEM), Vickers micro-hardness tester and x-ray diffractomer (XRD). The main concerns of this paper include (i) developing a new strategy to prepare UFG pure copper with enhanced mechanical properties; (ii) exploring the relationships between hardness and microstructure of the UCC samples; and (iii) revealing the effect of strain rate on the machining results.

\section{Theoretical model of strain rate in UCC}

\subsection{Motion characteristics analysis of UCC}

In the machining process, a unit on the cutting edge was taken to establish the cutting edge path equation. In TCC, the cutting edge path equation was as follows:

$$
\left\{\begin{array}{c}
X^{\prime}(t)=\left(r-a_{p}\right) \cdot \sin (2 \pi n t / 60) \\
Y^{\prime}(t)=\left(r-a_{p}\right) \cdot \cos (2 \pi n t / 60) \\
Z^{\prime}(t)=v_{f} \cdot t
\end{array}\right.
$$

Where, $r$ is the radius of workpiece, $a_{p}$ is the cutting depth, $n$ is the spindle speed, $v_{f}$ is the feed speed of cutting tool.

In the UCC process, the cutting edge path equation in one vibration period was as follows: 


$$
\left\{Y(t)=A_{Y} \sin (2 \pi f t)\right.
$$

Where, $A_{Y}$ is the amplitude of ultrasonic longitudinal vibration, $f$ is the ultrasonic vibration frequency.

UCC was based on the TCC, which applied periodic vibration with the same frequency in the cutting direction. The cutting edge path equation of UCC was as follows:

$$
\left\{\begin{array}{c}
X^{\prime}(t)=\left(r-a_{p}\right) \cdot \sin (2 \pi n t / 60) \\
Y^{\prime}(t)=\left(r-a_{p}\right) \cdot \cos (2 \pi n t / 60)+A_{Y} \sin (2 \pi f t) \\
Z^{\prime}(t)=v_{f} \cdot t
\end{array}\right.
$$

The comparison of cutting edge trajectory between TCC and UCC was shown in Fig.1. Due to the effect of ultrasonic high-frequency vibration, the cutting edge and the workpiece were periodically separated and contacted. This special movement will make the chip get different plastic deformation from TCC in the machining process.

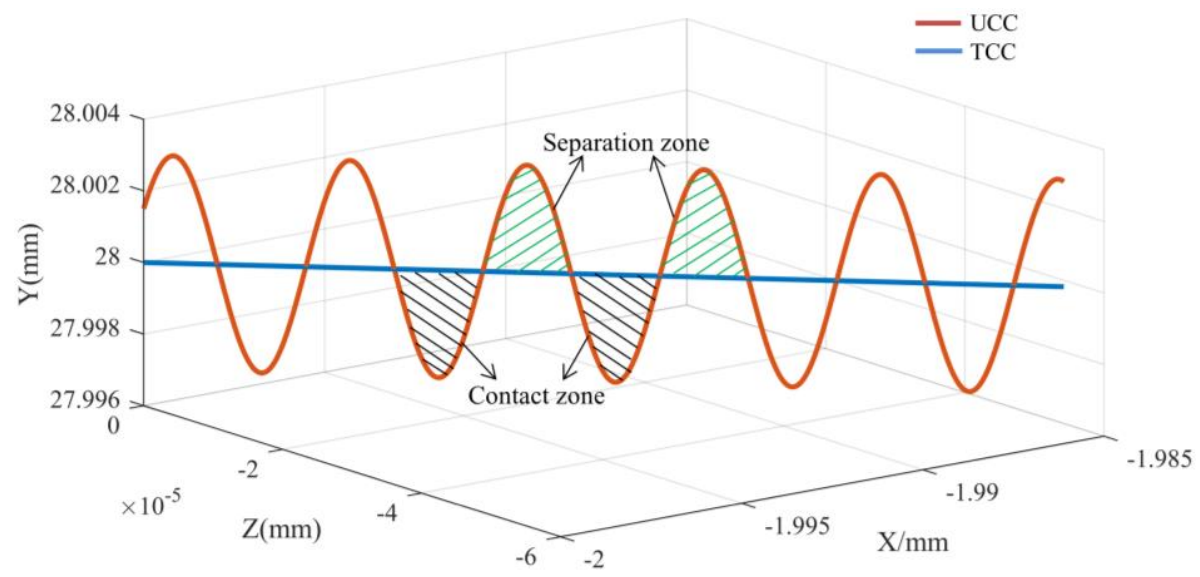

Fig.1 Comparison of cutting edge trajectory between TCC and UCC

\subsection{Strain rate model of UCC}

TCC is an alteration of conventional orthogonal machining, which can be considered a shear plane-strain process. The chip thickness in orthogonal machining is formed freely while it is set as a prior in TCC. The main form of deformation in machining is the shear slip of materials. The chip are mainly affected by two deformation zones in TCC machining, including the primary shear zone (the first deformation zone), the extrusion and friction zone of tool and material (the second deformation zone). The schematic diagram of shear deformation for TCC and the associated geometric parameters are shown in Fig.2.

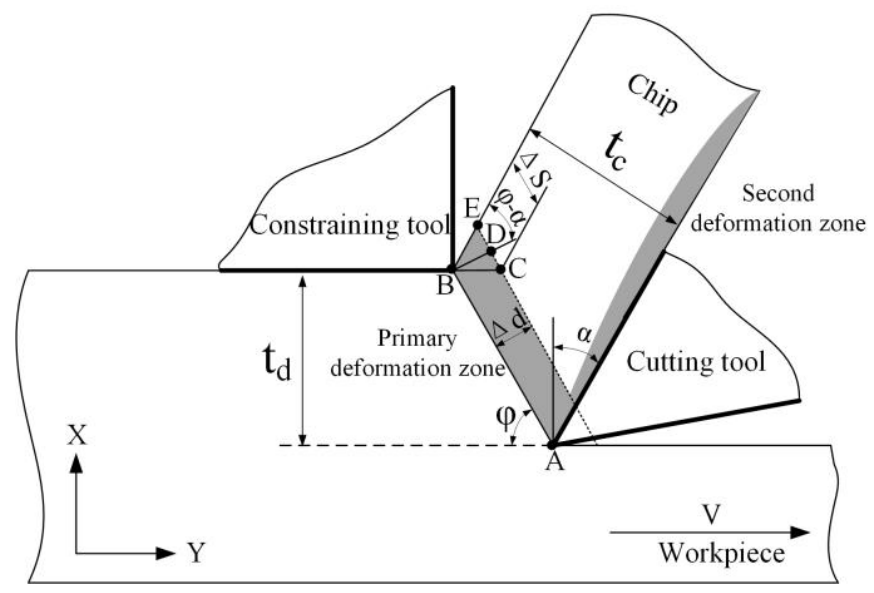

Fig.2 Schematic diagram of shear deformation for TCC and associated geometric parameters 
The shear strain imposed on the chip during the chip formation in TCC is defined as:

$$
\gamma=\frac{\Delta S}{\Delta d}=\frac{C E}{B D}=\frac{C D+D E}{B D}=\cot \varphi+\tan (\varphi-\alpha)
$$

Where, $\varphi$ is the shear angle, $\alpha$ is the tool rake angle.

In order to characterize the deformation degree of chip, the chip compression ratio $\lambda$ is introduced:

$$
\lambda=\frac{t_{c}}{t_{d}}=\frac{A B \sin \left(90^{\circ}-\varphi+\alpha\right)}{A B \sin \varphi}
$$

From Eq. (5):

$$
\tan \varphi=\frac{\cos \alpha}{\lambda-\sin \alpha}
$$

From Eq. (4) and Eq. (6), the relationship between $\gamma$ and $\lambda$ can be obtained as follows:

$$
\gamma=\frac{\lambda^{2}-2 \lambda \sin \alpha+1}{\lambda \cos \alpha}=\frac{\lambda}{\cos \alpha}+\frac{1}{\lambda \cos \alpha}-2 \tan \alpha
$$

In general, the approximation of the deformation zone as a "shear plane", albeit of small thickness $(\Delta d)$, is a reasonable model and is applied in the present study to estimate the strain rate. Then, the strain rate $[19,20]$ under localized deformation can be approximated as:

$$
\dot{\varepsilon}=\frac{\gamma}{\Delta t}=\frac{\Delta s}{\Delta d \Delta t}=\frac{V_{s}}{\Delta d}
$$

Where, $V_{s}$ is the shear speed, $\Delta d$ is the primary deformation zone (PDZ) thickness, which is typically taken as $50 \mu \mathrm{m}$ using the particle image velocimetry (PIV) technique [21, 22].

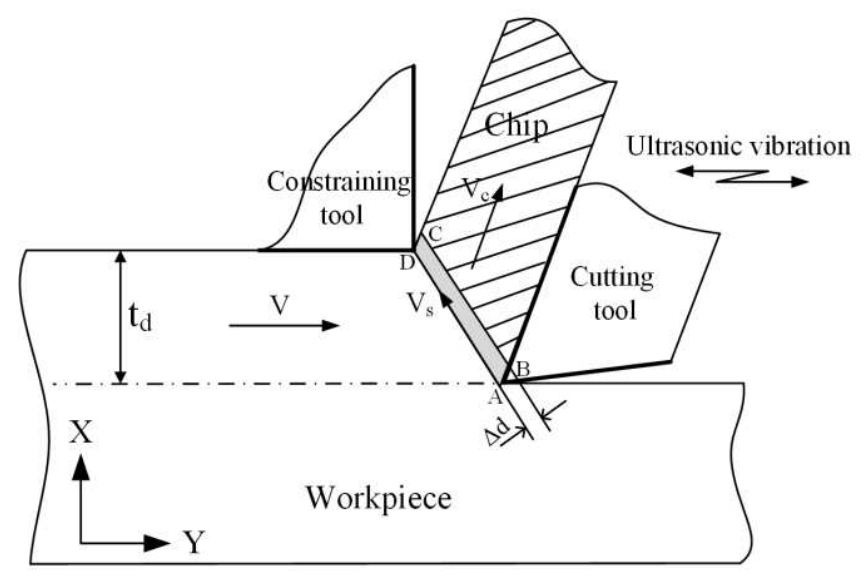

Fig.3 The shear plane model

The shear plane model is shown in Fig.3. $\mathrm{ABCD}$ is the primary deformation zone, $V$ is the cutting speed, $V_{c}$ is the chip speed, $V_{S}$ is the shear speed. $V, V_{c}$ and $V_{s}$ can form a closed vector graph. The shear speed [23] is calculated by:

$$
V_{s}=\frac{\cos \alpha}{\cos (\varphi-\alpha)} V
$$

The cutting speed $V$ can be obtained from Eq. (3):

$$
V(t)=\frac{\pi n\left(r-a_{p}\right)}{30} \cdot \cos (2 \pi n t / 60)+2 \pi f A_{Y} \cdot \sin (2 \pi f t)
$$


From Eq. (8), Eq. (9) and Eq. (10), the maximum strain rate of UCC can be obtained as follows:

$$
\dot{\varepsilon}_{\text {max }}=\frac{\cos \alpha}{\cos (\varphi-\alpha) \Delta d} \cdot\left[\frac{\pi n\left(r-a_{p}\right)}{30} \cdot \cos (2 \pi n t / 60)+2 \pi f A_{Y} \cdot \sin (2 \pi f t)\right]
$$

From Eq. (11), it can be obtained that the maximum strain rate $\dot{\varepsilon}_{\max }$ in UCC is proportional to the ultrasonic amplitude $A_{Y}$. The grain refinement is not only related to the strain of plastic deformation of the material, but also to the strain rate, so the result of UCC at high strain rate will be more excellent.

\section{Simulation and validation of strain rate in UCC}

\subsection{FEM details}

FEM is adopted to simulate machining with great success. The 3D model of the cutting tool, constraining tool and workpiece are shown in Fig.4. The tool material is carbide and the workpiece material is pure copper, the material properties of workpiece are shown in Table 1 [3]. In order to achieve ultrasonic vibration of the cutting tool and constraining tool, the tool reference point was given a feed speed and periodic displacement along the cutting direction.

The key to ensure the accuracy of UCC simulation is the constitutive model. The Johnson-cook constitutive model is able to express strain hardening, strain rate strengthening and thermal softening at high strain rate, which is more consistent with actual machining. So J-C constitutive model and J-C failure criteria were adopted in this paper. The J-C constitutive model parameters and failure criteria parameters of pure copper are shown in Table 2 and Table 3, respectively [24].

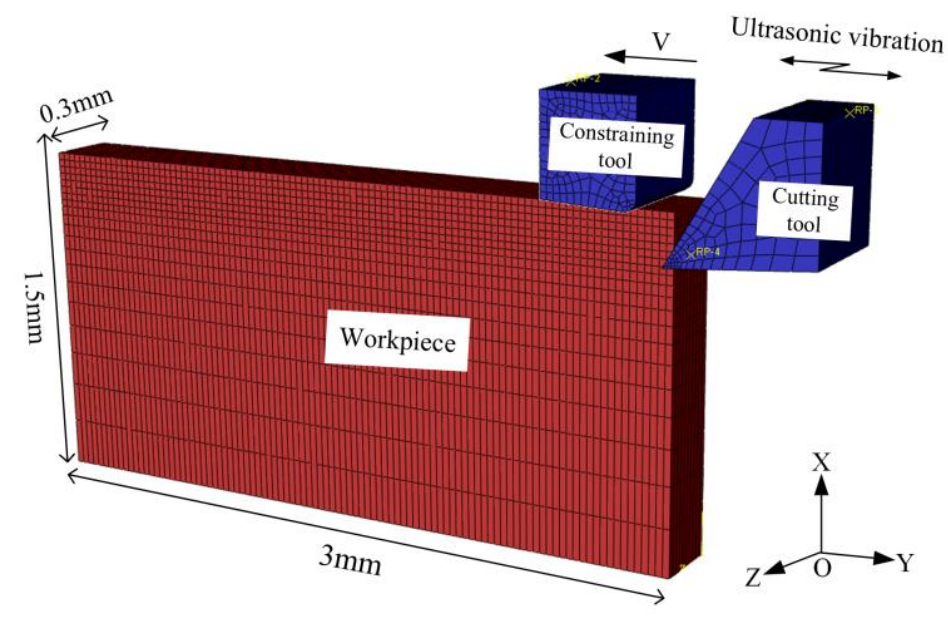

Fig.4 Finite element model of UCC

Table 1 Material properties of pure copper [3]

\begin{tabular}{cc}
\hline Parameters & Reference value \\
\hline Density/ $\left(\mathrm{kg} / \mathrm{m}^{3}\right)$ & 8960 \\
Yang's Model/ GPa & 108 \\
Poisson's ratio & 0.333 \\
Specific heat capacity $/(\mathrm{J} / \mathrm{kg} \cdot \mathrm{K})$ & 3.16032 \\
Melting point $/ \mathrm{K}$ & 1356 \\
Thermal conductivity $/(\mathrm{W} /(\mathrm{m} \cdot \mathrm{K}))$ & 122.613 \\
Expansion coefficient $/(\mu \mathrm{m} /(\mathrm{m} / \mathrm{K}))$ & 17.5 \\
\hline
\end{tabular}


Table 2 J-C constitutive parameters of pure copper [24]

\begin{tabular}{cccccccc}
\hline$A$ & $B$ & $C$ & $m$ & $n$ & $\dot{\varepsilon}_{0}$ & $T_{r}$ & $T_{m}$ \\
\hline 90 & 292 & 0.025 & 1.09 & 0.31 & 1 & 300 & 1356 \\
\hline
\end{tabular}

Table 3 J-C failure parameters of pure copper [24]

\begin{tabular}{ccccc}
\hline$D_{1}$ & $D_{2}$ & $D_{3}$ & $D_{4}$ & $D_{5}$ \\
\hline 1.08 & 4.89 & 3.03 & 0.014 & 1.12 \\
\hline
\end{tabular}

3.2 Simulation results and analysis of strain rate

In order to investigate how the ultrasonic vibration affects material properties and microstructure, the correlation between the machining parameters (e.g., amplitude) and deformation parameters (e.g., strain rate) are required. The literature shows that at high strain rate, the dislocation distribution will be more random and uniform and the grain size will also decrease $[25,26]$. Therefore, the study of chip strain rate in the deformation zone has guiding significance for the production of UFG pure copper.

The strain rate distribution in the chip with different ultrasonic amplitudes is shown in Fig.5. The strain rate is changed by the variation in amplitude: strain rate is low at small amplitude and increases with the increase of amplitude. The maximum values of strain rate are $1.636 \times 10^{4}, 3.72 \times 10^{4}, 3.996 \times 10^{4}$ and $5.482 \times 10^{4}$, corresponding to the four amplitudes from $0 \mu \mathrm{m}$ to $3 \mu \mathrm{m}$. When $A_{Y}$ is $3 \mu \mathrm{m}$, the strain rate is maximum. The maximum value of strain rate increases from $1.636 \times 10^{4}$ to $3.72 \times 10^{4}$ as $A_{Y}$ increases from $0 \mu \mathrm{m}$ to $1 \mu \mathrm{m}$, representing a difference value of $2.084 \times 10^{4}$. It shows that ultrasonic vibration can more significantly increase the strain rate in the deformation zone. The maximum value of strain rate increases from $3.72 \times 10^{4}$ to $3.996 \times 10^{4}$ as $A_{Y}$ increases from 1 $\mu \mathrm{m}$ to $2 \mu \mathrm{m}$, representing a difference value of $0.276 \times 10^{4}$. However, it increases from $3.996 \times 10^{4}$ to $5.482 \times 10^{4}$ while $\mathrm{A}_{Y}$ increases from $2 \mu \mathrm{m}$ to $3 \mu \mathrm{m}$, with a difference of $1.486 \times 10^{4}$. It shows that the strain rate will increase while the amplitude increases.
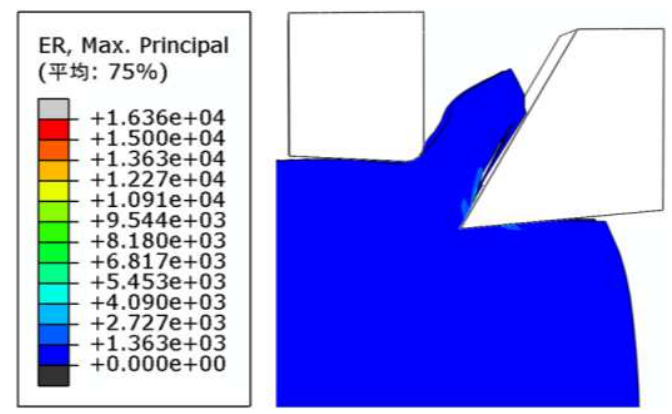

(a)

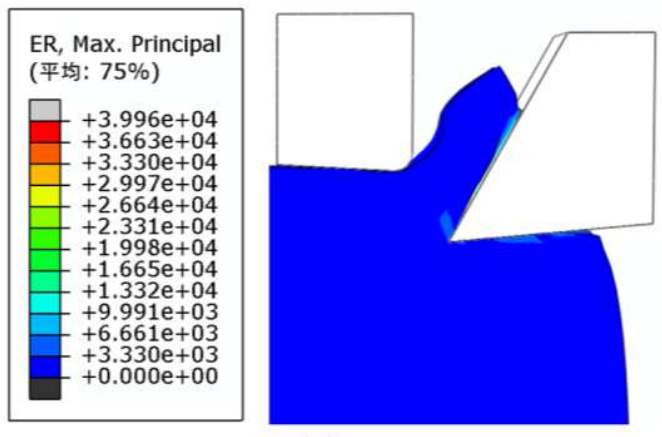

(c)
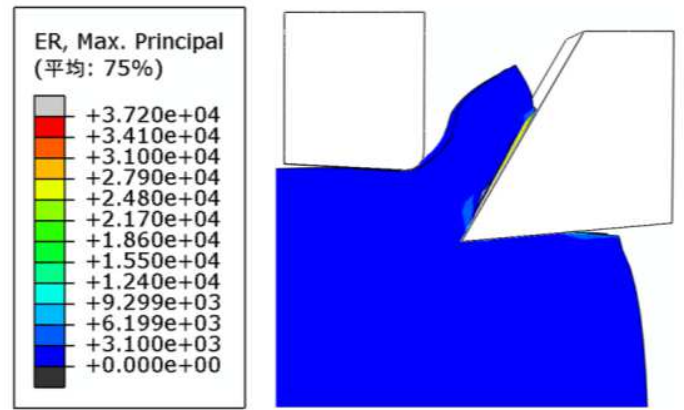

(b)
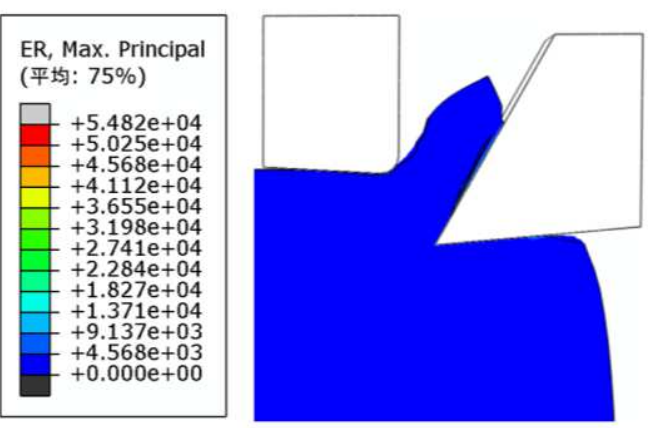

(d) 
Fig.5 The distribution of strain rate with different ultrasonic amplitudes: (a) $A_{Y}=0 \mu \mathrm{m}$, (b) $A_{Y}=$ $1 \mu \mathrm{m}$, (c) $A_{Y}=2 \mu \mathrm{m}$, (d) $A_{Y}=3 \mu \mathrm{m}$

The strain rate changes in the chip with different ultrasonic amplitudes are shown in Fig.6. The same point on workpiece was selected to compare the strain rate change. The simulation results show that the strain rate in the chip will gradually increases with the increase of amplitude $A_{Y}$.

The effect of strain rate on refining the internal structure and modifying the surface structure cannot be ignored. When the material is mechanically deformed to produce high-density dislocation, the internal structure will be refined and the surface structure will be modified. The increase of dislocation density is not only related to the strain of plastic deformation, but also to the strain rate. This paper demonstrates that ultrasonic vibration technology can significantly increase the cutting strain rate.

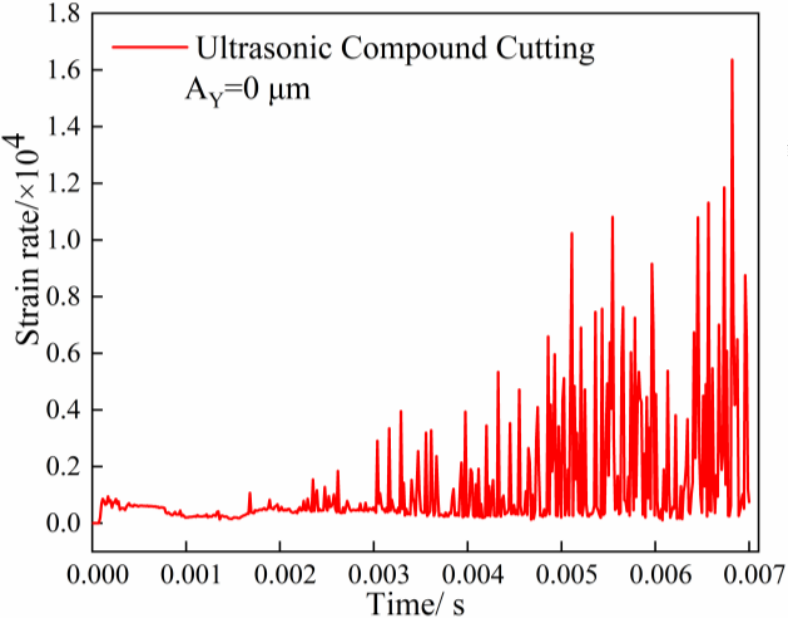

(a)

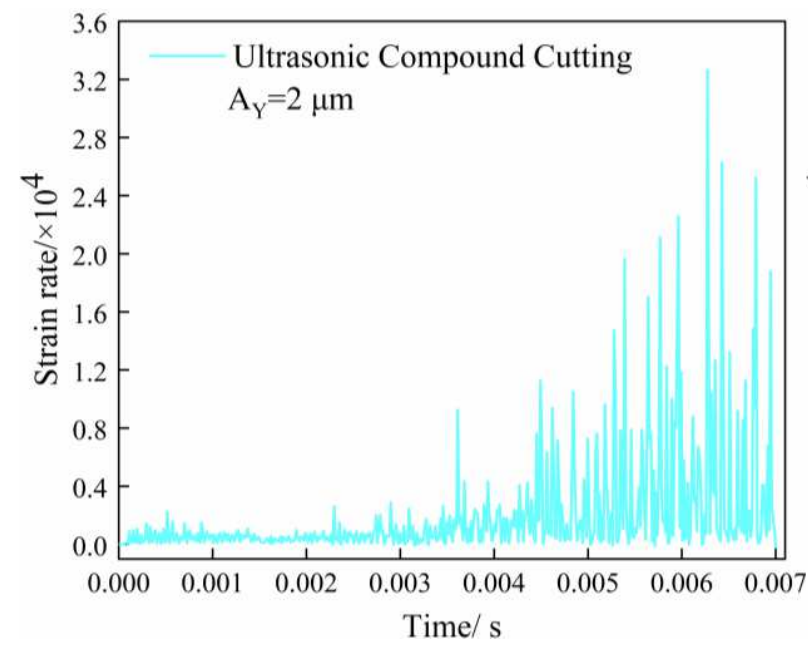

(c)

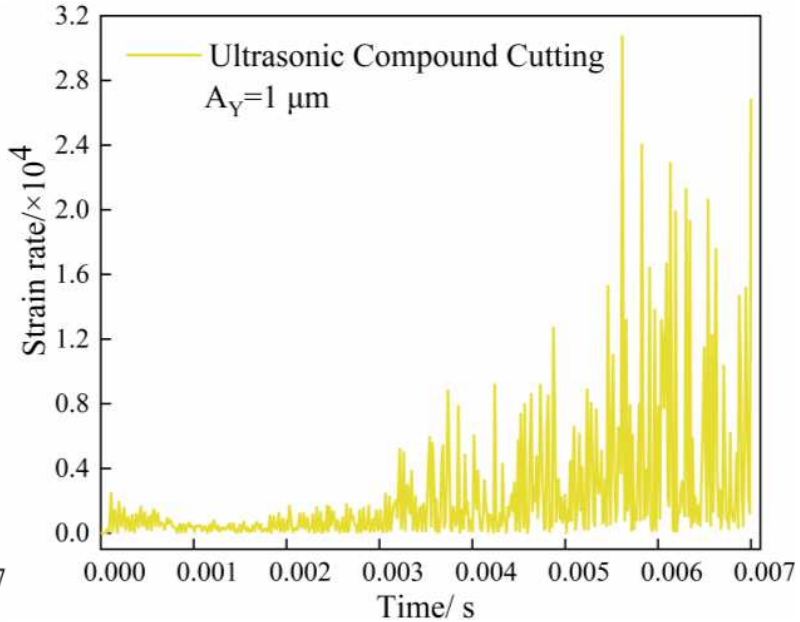

(b)

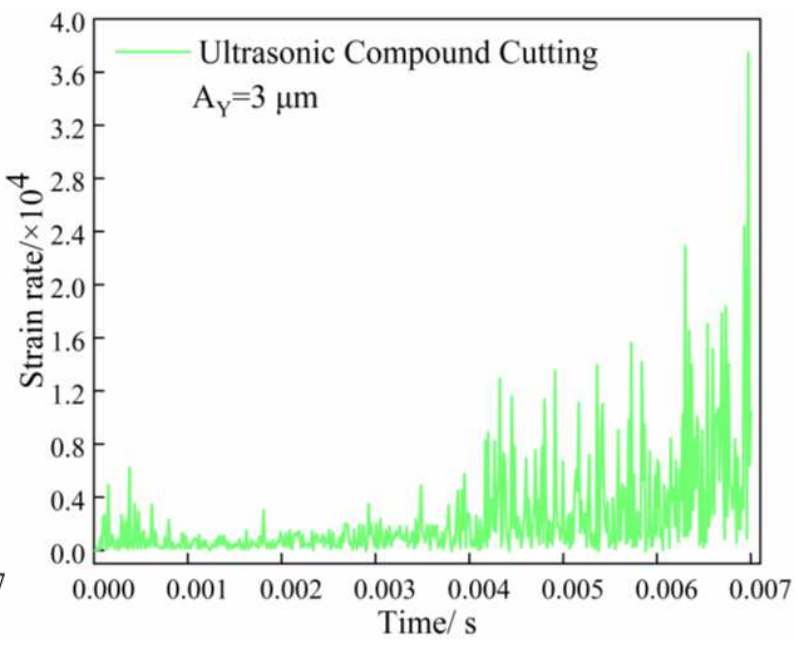

(d)

Fig.6 Strain rate changes with different ultrasonic amplitudes: (a) $A_{Y}=0 \mu \mathrm{m}$, (b) $A_{Y}=1 \mu \mathrm{m}$, (c) $A_{Y}=2 \mu \mathrm{m}$, (d) $A_{Y}=3 \mu \mathrm{m}$

\section{Microstructure and properties experiment of UCC}

\subsection{Experimental details}

The experiment setup is shown in Fig.7. The experiment setup is composed of high-frequency vibration system and extrusion cutting system. The high-frequency vibration system is composed of ultrasonic generator, transducer and horn, the extrusion cutting system is composed of cutting tool, constraining tool and connecting 
frame. The two systems cooperate with each other to generate ultrasonic high-frequency vibration for the cutting tool and constraining tool.

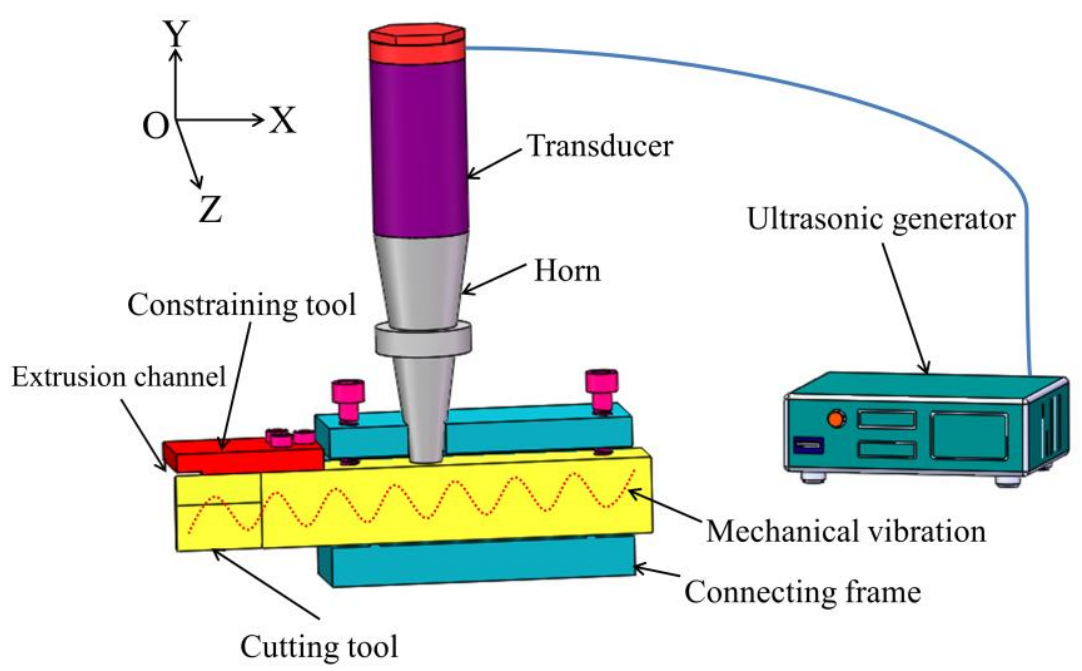

Fig.7 Schematic diagram of UCC setup

The test conditions in this article are shown in Table 4. In order to minimize the influences of strain rate and temperature variations, the cutting speed was kept slow, and the work material was continuously fed into the extrusion channel with formation of the geometrically controlled chip. In order to ensure 2D deformation, the chip width was kept much larger than the thickness of the unformed chip. At that time, the strain along the chip width direction was minimal. All machining experiments were conducted on a universal lath (CA6140B/A), using machining oil (SAE-30) as lubricant and coolant. The experimental setup of UCC is illustrated in Fig.8.

Table.4 Test conditions

\begin{tabular}{cc}
\hline Parameters & Reference value \\
\hline Spindle speed $\mathrm{n}(\mathrm{r} / \mathrm{min})$ & 25 \\
Feed speed $V_{f}(\mathrm{~mm} / \mathrm{r})$ & 0.28 \\
Cutting depth $a_{p}(\mathrm{~mm})$ & 1.6 \\
Ultrasonic amplitude $A_{Y}(\mu \mathrm{m})$ & $0 、 1 、 2 、 3$ \\
Machining oil & SAE-30 \\
\hline
\end{tabular}

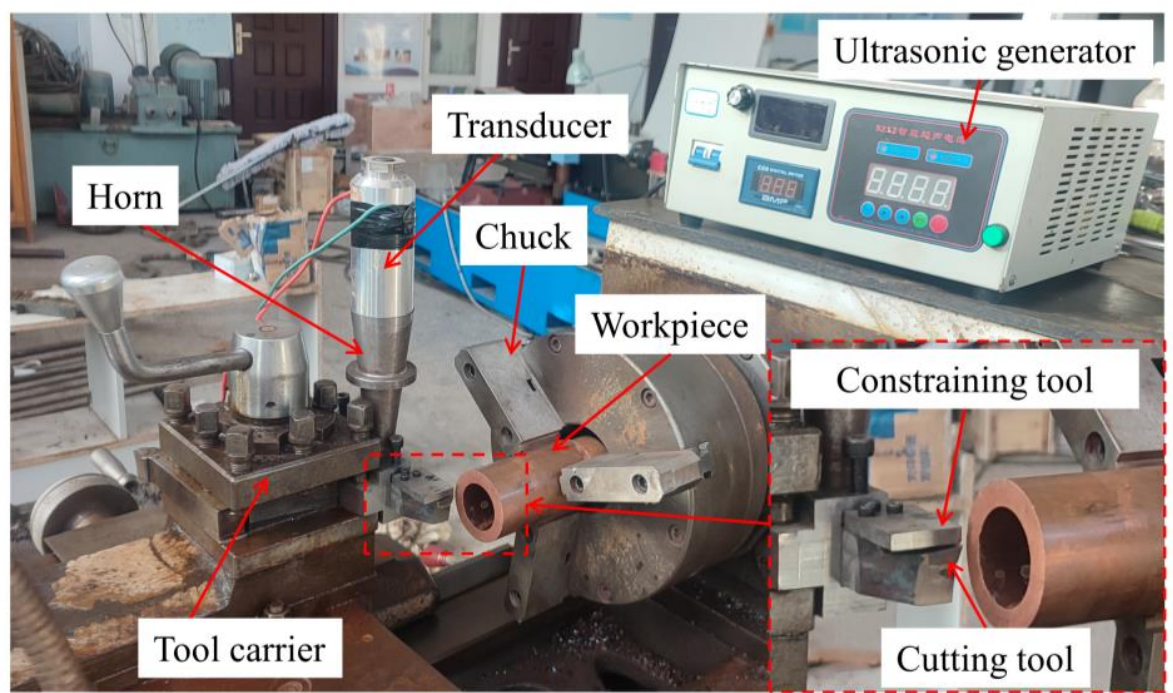




\section{Fig.8 Real experimental setup of the UCC}

Microstructures of all samples were examined in detail using the OM and SEM. For this purpose, the samples were mechanically polished with abrasive paper of 600, 1000, 1500, 2000 and 3000 grit in sequence, followed by fine polishing with the diamond paste of $1 \mu \mathrm{m}$ to the mirror finish. Grinding of the chip was started from the surface coming in contact with the tool rake face. Reagent $\left(5 \mathrm{~g} \mathrm{FECL}_{3}, 50 \mathrm{~mL} \mathrm{HCl}\right.$, and $100 \mathrm{~mL} \mathrm{H}_{2} \mathrm{O}$ ) was adopted to etch the samples. As for SEM study, in order to avoid the decrease of conductivity affecting the observation result, so the samples were sprayed with gold. The formation of different phases of the samples was analyzed using XRD by scanning in the range $2 \theta 20^{\circ}-90^{\circ}$. $\theta-2 \theta$ accurate scans with a step size of $0.02^{\circ}$ were performed at room temperature. Micro-hardness tests were carried out with a Vickers micro-hardness tester at a load of $50 \mathrm{~g}$ for a dwell time of $15 \mathrm{~s}$. An average was taken from at least 15 readings for each sample. The test positions of OM, SEM, XRD and micro-hardness were chosen on the plane closed to the tool rake face.

4.2 Experimental results and analysis of microstructure

OM images of the starting material and samples subjected to UCC are illustrated in Fig.9. The OM image of the starting material is shown in Fig. 9(a) and the OM image processed by the image-pro-plus (IPP) software is shown in Fig. 9(b). The microstructure of starting material mainly consists of grains in the range of 10-30 $\mu \mathrm{m}$ with a mean grain size of $18.15 \mu \mathrm{m}$, and also grains of more than $50 \mu \mathrm{m}$ can be observed.

The OM images of UCC samples are shown in Fig. 9(c)-9(f). After subjected to UCC, the grains were highly refined. The IPP software was not easy to capture grain boundaries, so the linear intercept method [27] was used, the equation is as follows:

$$
\bar{l}=\frac{L}{P_{i}}
$$

Where, $\bar{l}$ is the average intersection length, $L$ is the length of test line, $P_{i}$ is the number of intersections between grain boundaries and test line. At least 200 grains and sub-grains with relatively clear boundaries were counted and calculated employing linear intercept method to estimate the average grain size. For those chips with elongated structures, the mean width (along small dimension) of grain is considered as the grain size [28].

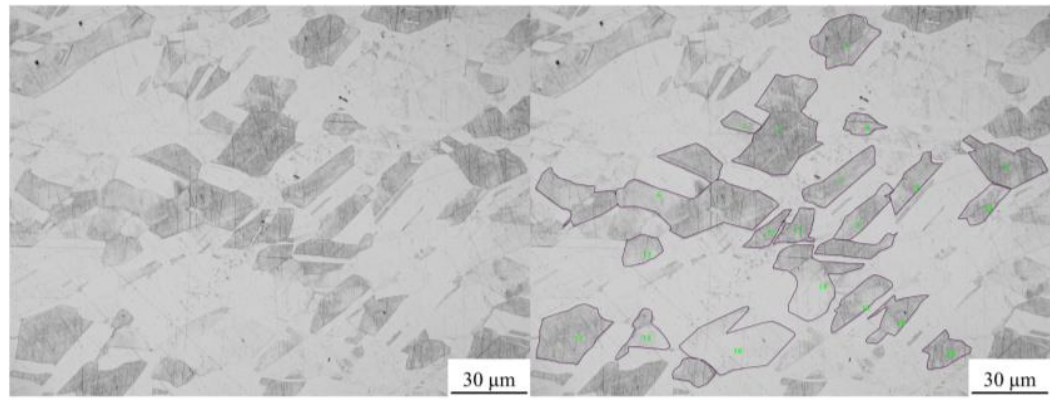

(a)

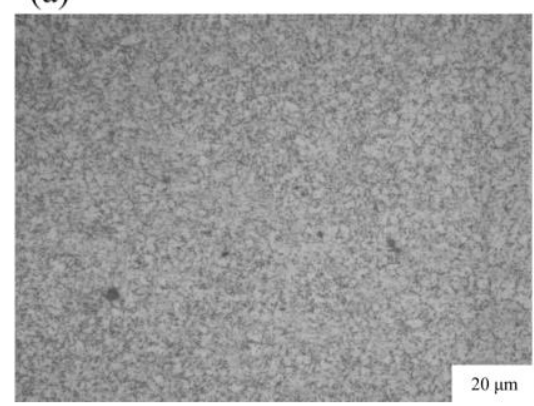

(c) (b)

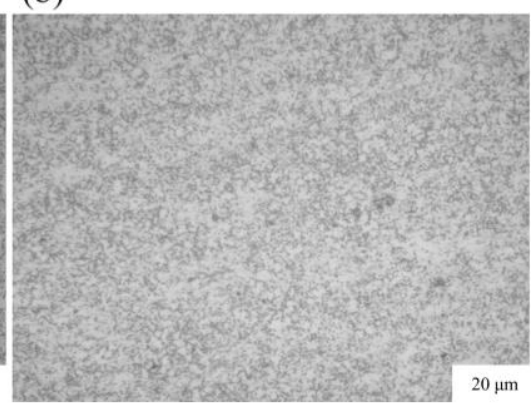

(d) 


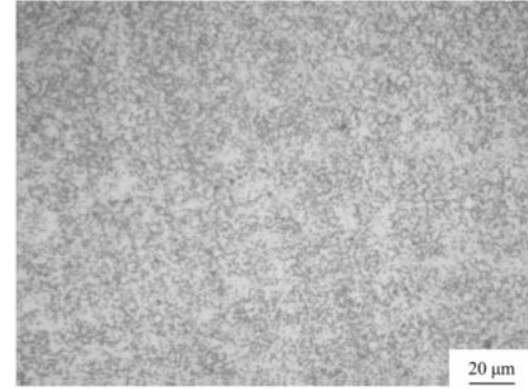

(e)

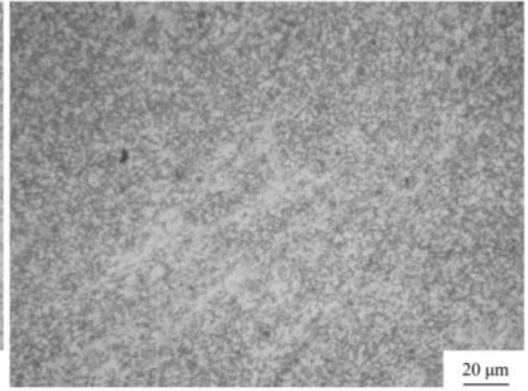

(f)

Fig.9 OM images of the (a) starting material, (b) IPP sample, (c) UCC sample for $A_{Y}=0 \mu \mathrm{m}$, (d) UCC sample for $A_{Y}=1 \mu \mathrm{m}$, (e) UCC sample for $A_{Y}=2 \mu \mathrm{m}$, (f) UCC sample for $A_{Y}=3 \mu \mathrm{m}$

The grain size distributions are shown in Fig.10. The average values of the sample grains are $3.86 \mu \mathrm{m}, 3.30$ $\mu \mathrm{m}, 3.11 \mu \mathrm{m}$ and $2.66 \mu \mathrm{m}$, corresponding to the four amplitudes from $0 \mu \mathrm{m}$ to $3 \mu \mathrm{m}$. The results show that the grain refinement of chip structure will gradually increases with the increase of ultrasonic amplitude. As the ultrasonic amplitude increases, the dynamic impact on the material surface becomes larger, and the plastic deformation of the chips will increase. At the same time, the grain refinement process includes: formation of dislocation walls through propagation, slip, annihilation and recombination of the dislocations, and the wide grain will be divided into new fine grain.

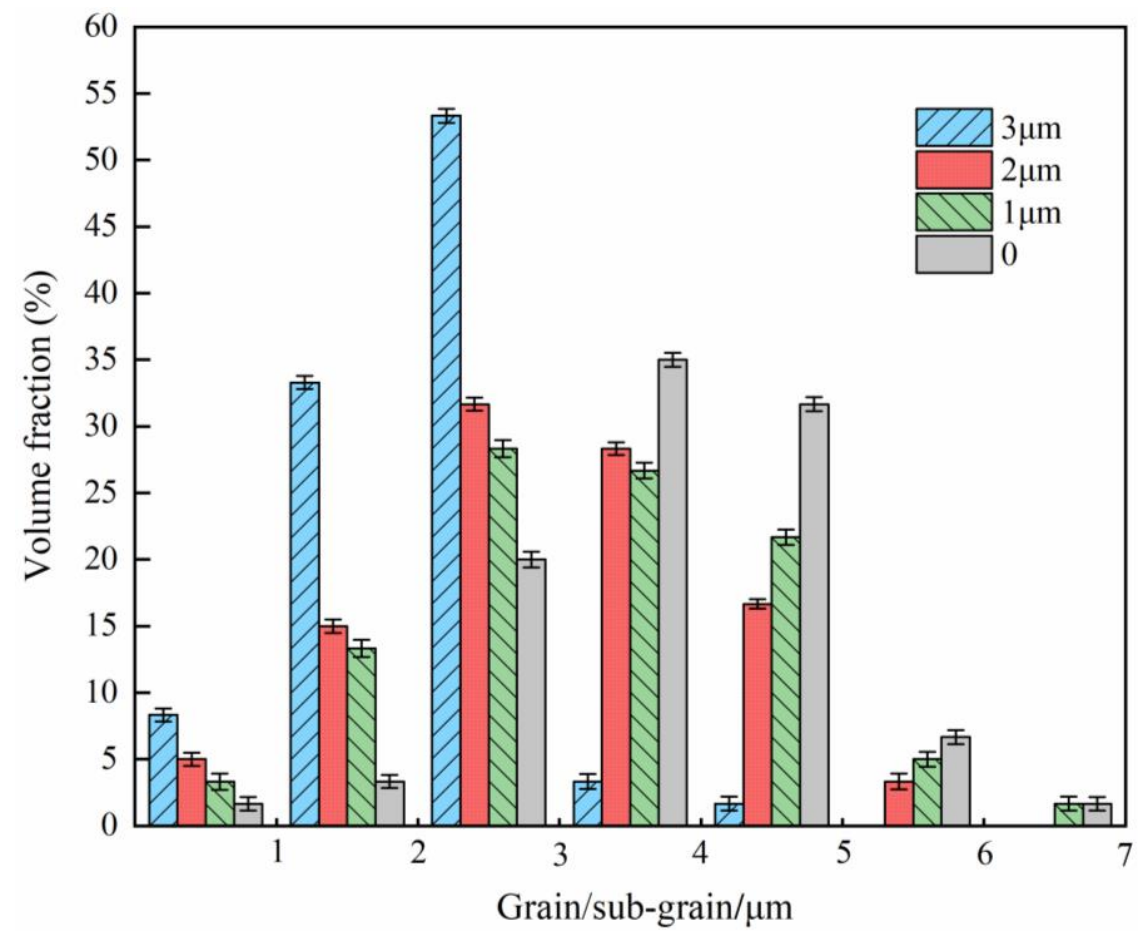

Fig.10 Grain/sub-grain size statistic distributions of the UCC samples

In order to obtain more detail information about microstructure features, SEM technology is introduced. The SEM images of UCC samples are shown in Fig.11. When the amplitude is $0 \mu \mathrm{m}$, the average grain size of the starting material is refined from $18.15 \mu \mathrm{m}$ to $3.86 \mu \mathrm{m}$, indicating that TCC is an effective method to produce UFG pure copper. When the ultrasonic amplitude is $3 \mu \mathrm{m}$, the average grain size of the sample is about $69 \%$ of the TCC chip, indicating that ultrasonic vibration can significantly improve the efficiency of UCC. The results show that the strain rate in the deformation field can be increased by increasing the ultrasonic amplitude, and the grain size of chip will decrease. 


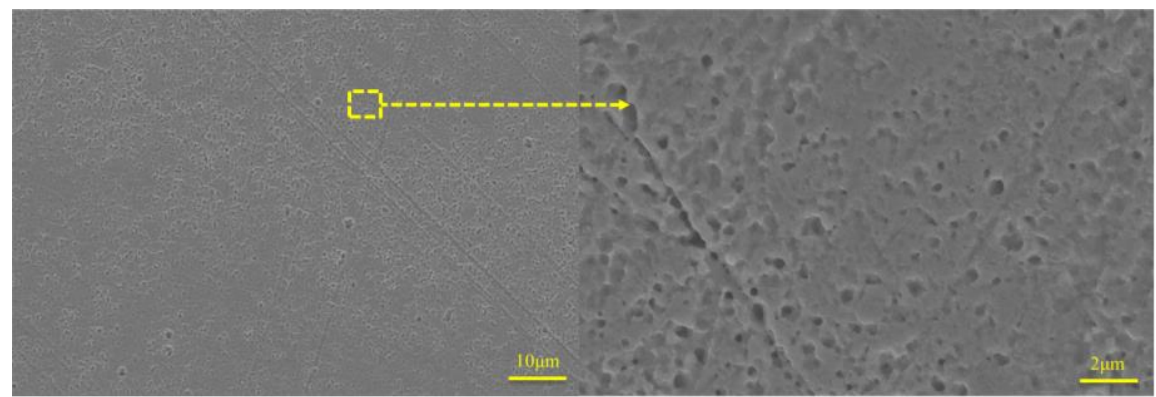

(a)

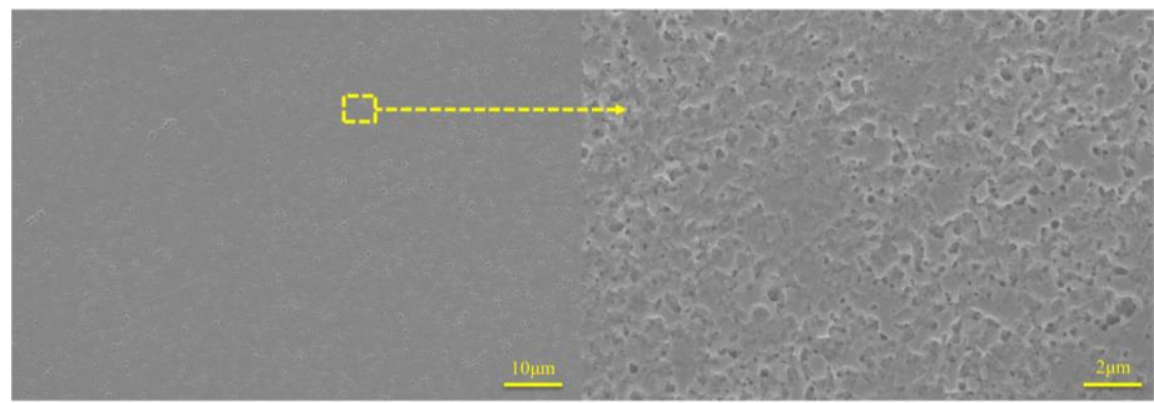

(b)

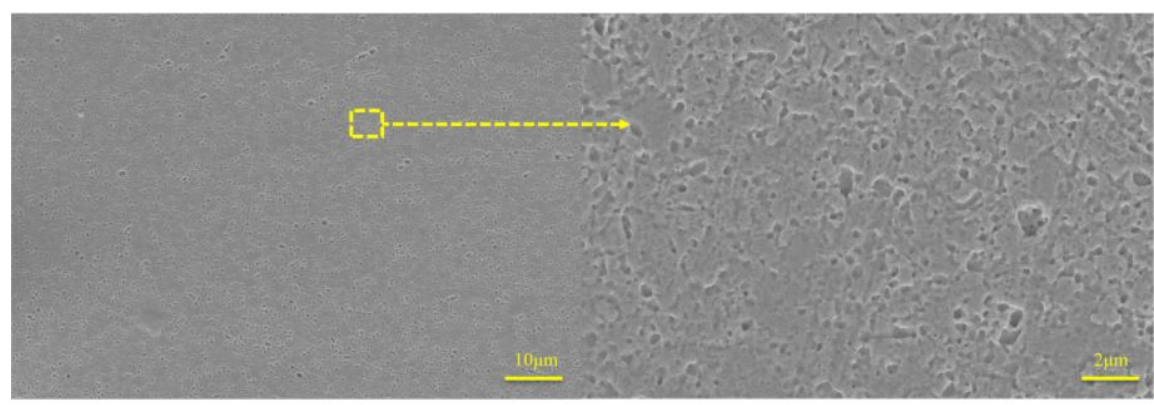

(c)

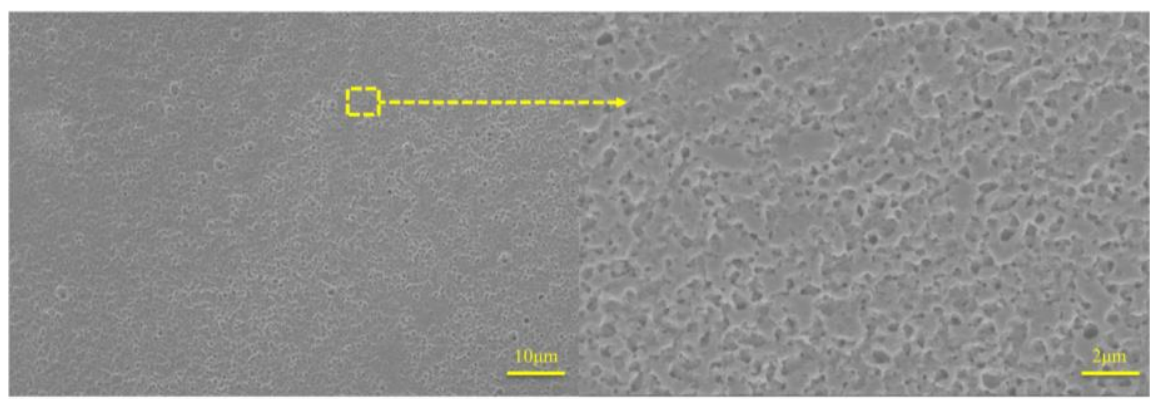

(d)

Fig.11 SEM images and local enlarged drawing of the (a) UCC sample for $A_{Y}=0 \mu \mathrm{m}$, (b) UCC sample for $A_{Y}=1 \mu \mathrm{m}$, (c) UCC sample for $A_{Y}=2 \mu \mathrm{m}$, (d) UCC sample for $A_{Y}=3 \mu \mathrm{m}$

4.3 Experimental results and analysis of micro-hardness

The micro-hardness of UCC samples with different ultrasonic amplitudes are shown in Fig.12. The hardness of the starting material is $86 \mathrm{HV}$. The surface of UCC chip will produce work hardening, and the surface hardening will become larger with the increase of ultrasonic amplitude. The hardness of the UCC sample is $124 \mathrm{HV}$ when the amplitude is $3 \mu \mathrm{m}$, which is about $8 \%$ higher than the hardness of TCC chip. The work hardening of the chip surface is closely related to the microstructure and dislocation density of the material [29]. The improvement concerning the strength or hardness of pure copper may be mainly attributed to the following: (i) grain refinement 
strengthening, (ii) dislocation strengthening.

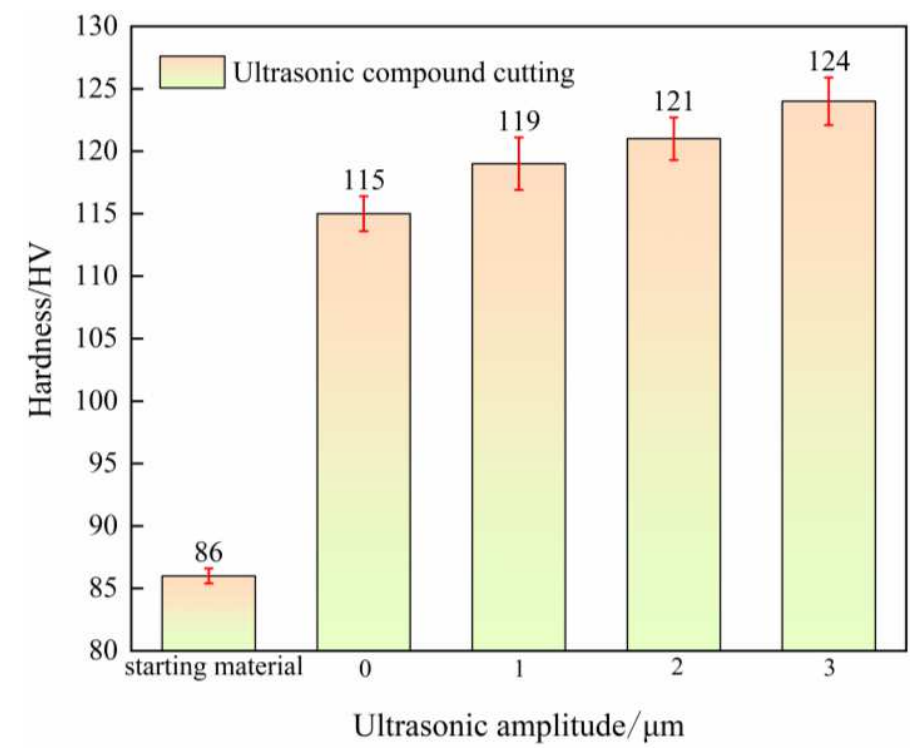

Fig.12 Micro-hardness of UCC samples with different ultrasonic amplitudes

Because the deformation resistance of grain boundary is very large, and the deformation of each grain will be restrained by the surrounding grains, so the hardness of pure copper chip always increases with the refinement of grain (i.e., the increase in the total area of grain boundaries). Therefore, the large enhancement in hardness of UCC samples could be directly attributed to the grain refinement strengthening, one of the main strengthening mechanisms of material subjected to plastic deformation. Grain refinement strengthening is generally described by the Hall-Patch equation in which the strength of materials is inversely proportional to the grain size. Here, the hardness version is used instead of the flow stress version [30].

$$
H_{V}=H_{0}+K_{H} d^{-1 / 2}
$$

Where, $H_{V}$ is the hardness, $H_{0}$ and $K_{H}$ are the material constants, $d$ is the average grain size of materials. Obviously, the hardness increases with the decreasing of the average grain size.

To examine the Hall-Patch relationship, the Vickers hardness values of the UCC samples in Fig.12 were plotted as a function of $d^{-1 / 2}$, which is shown in Fig.13. This indicates that the UCC samples follow the linear relationship described by Eq. (13). Accordingly, grain refinement strengthening makes significant contribution to the hardness enhancement of all the samples subjected to UCC.

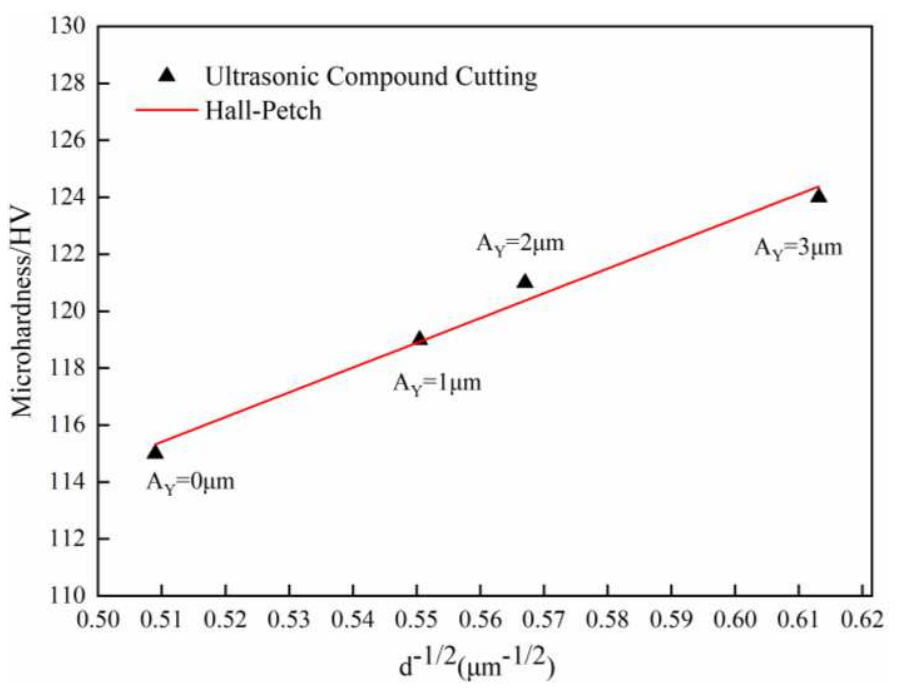




\section{Fig.13 Micro-hardness of samples processed by UCC as a function of $d^{-1 / 2}$}

In this paper, dislocation strengthening is another important strengthening mechanism for pure copper chip. Because higher dislocation density in the UCC samples forms much more dislocation tangles, which act as barriers against the dislocation movement, thus hardening the materials. Theoretically, the contribution of dislocation to material strength can be described by the Bailey-Hirsch equation [31].

$$
\sigma_{d}=M \alpha_{D} G b \rho^{\frac{1}{2}}
$$

Where, $M$ is the Taylor factor, $\alpha_{D}$ is the strength coefficient, $G$ is the shear modulus, $b$ is the Burgers vector and $\rho$ is the dislocation density. As the strength is directly proportional to the hardness of materials, so the higher the dislocation density, the greater the hardness of materials.

The diffraction patterns of XRD for UCC samples are shown in Fig.14 (a). In the XRD diffraction patterns, the dislocation density is mainly determined by the full width at half maximum (FWHM) of the diffraction peak [32-33]. Fig.14 (b) is the fitted peak of $A_{Y}=3 \mu \mathrm{m}$, the corrected FWHM for peak was 0.2789. When the amplitudes are $0 \mu \mathrm{m}, 1 \mu \mathrm{m}$, and $2 \mu \mathrm{m}$, the corresponding FWHM are $0.23749,0.23948$ and 0.26345 , respectively. The XRD results show that the FWHM of peak increases with the increase of amplitude $A_{Y}$, and reaches the maximum when the amplitude is $3 \mu \mathrm{m}$. Therefore, ultrasonic vibration can improve the dislocation density of pure copper chip.

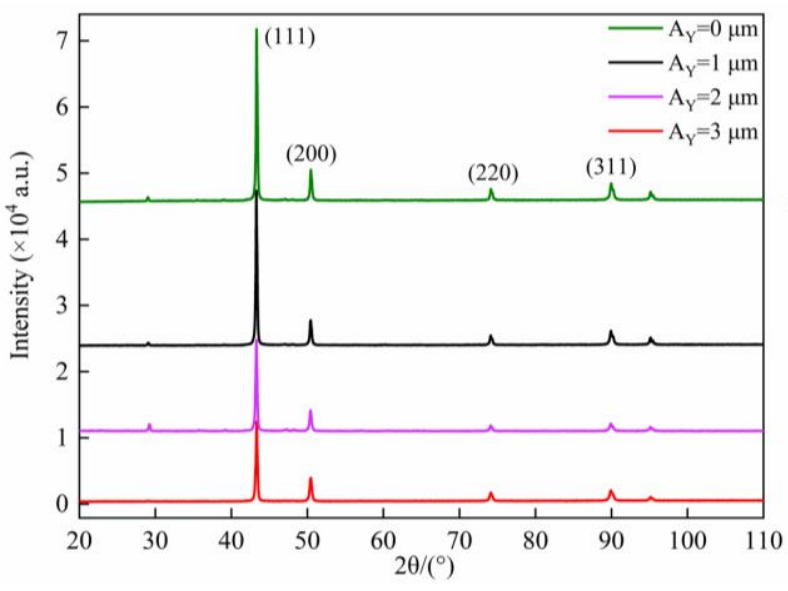

(a)

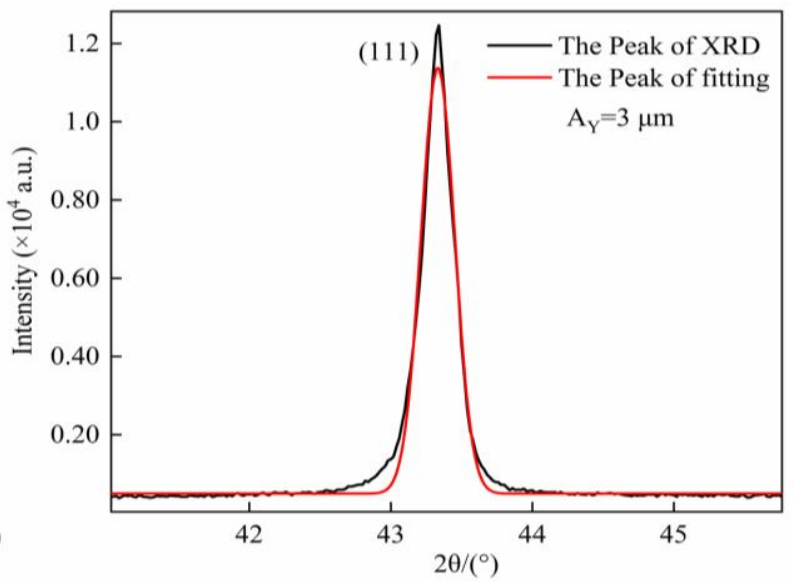

(b)

Fig.14 XRD patterns: (a) UCC samples, (b) the fitted peak of $A_{Y}=3 \mu \mathrm{m}$

\section{Conclusions}

In this paper, UCC was conducted with various amplitudes to investigate their comparative effects on chip microstructure and hardness of pure copper. The main observations can be summarized in following conclusions:

(1) The motion characteristics and strain rate model of UCC were discussed. According to the theoretical model of strain rate in UCC, if the ultrasonic amplitude increases, the strain rate in the primary shear zone will increase.

(2) The finite element model was established, and the strain rate in the shear deformation zone of UCC and TCC were compared and analyzed. The simulation results show that ultrasonic vibration can significantly increase the strain rate of formed chip.

(3) The experimental results show that the hardness of the UCC sample is $124 \mathrm{HV}$ when the amplitude is $3 \mu \mathrm{m}$, which is about $8 \%$ higher than the hardness of TCC chip. The main reasons are grain refinement strengthening and dislocation strengthening. Ultrasonic vibration can promote the dynamic recovery, and thereby form a complicated microstructure with high dislocation density. At the same time, when the material surface is subjected to dynamic 
impact force, the degree of grain refinement will increase.

(4) The results show that UCC with high strain rate can increase dislocation density, reduce the grain size and increase the hardness of pure copper chip. Therefore, UCC is a new technology for effectively preparing UFG pure copper with enhanced mechanical properties.

\section{Acknowledgments}

This work was supported by the Natural Science Foundation of Henan (No.202300410172) and Science and Technology Department of Henan Province (No. 212102210056) and National Natural Science Foundation of China (No.51675164).

\section{Declarations}

- Ethical approval This paper is new. Neither the entire paper nor any part of its content has been published or has been accepted elsewhere. It is not being submitted to any other journal as well.

\section{- Consent to participate Not applicable}

\section{- Consent to publish Not applicable}

- Author contributions Haimeng Sun: conceptualization, methodology, writing-original draft. Feng Jiao: conceptualization, methodology, software, supervision. Ying Niu: resources, supervision, writing-review \& editing. Zhuangfei Wang: software, investigation.

- Funding This work was supported by the Natural Science Foundation of Henan (No.202300410172) and Science and Technology Department of Henan Province (No. 212102210056) and National Natural Science Foundation of China (No.51675164).

- Conflict of interest The authors declare that they have no competing interests.

\section{- Availability of data and materials Not applicable}

\section{References:}

[1] Lei Qin, Xiaoying Xie, Junlong Li (2017) Development status and future development trend of MEMS technology. Modern Defence Technology 45(4):1-5. https://doi.org/10.3969/j.issn.1009-086x.2017.04.001

[2] Guangqiang Yan (2017) Deformation behavior and microstructure evolution of T-SHAPER micro-upsetting in ultrafine grained pure copper. Dissertation, Harbin Institute of Technology

[3] Jiayang Zhang, Wenjun Deng, Liangwei Liu, Xiaolong Yin, Wei Xia (2019) Study on forming extrusion cutting (FEC) producing fins and its forming performance. Journal of Mechanical Engineering 55(5):212-222. https://doi.org/10.3901/JME.2019.05.212

[4] Keyvani Ahmad, Naseri Majid, Imantalab Omid, Gholami Davood, Babaei Kazem, Fattah-alhosseini Arash (2021) Microstructural characterization and electrochemical behavior of nano/ultrafine grained pure copper through constrained groove pressing (CGP). Journal of Materials Research and Technology 11:1918-1931. https://doi.org/ 10.1016/J.JMRT.2021.02.039

[5] Mozghan Gholami, Mansour Mhaede, Filip Pastorek, Igor Altenberger, Branislav Hadzima, Manfred Wollmann, Lothar Wagner (2016) Corrosion behavior and mechanical properties of ultrafine grained pure copper with potential as a biomaterial. Advanced Engineering Materials 18(4):615-623. https://doi.org/10.1002/ADEM.201500269 
[6] Behzad Akbarzadeh, Hamid Gorji, Mohammad Bakhshi-Jooybari, Roohollah Jamaati, Mohammad Javad Mirnia (2021) Investigation of mechanical and microstructural properties of pure copper processed by combined extrusion-equal channel angular pressing (C-Ex-ECAP). The International Journal of Advanced Manufacturing Technology 113(7):2175-2191. https://doi.org/ 10.1007/S00170-021-06692-5

[7] Junting Luo, Wenlu Yu, Chenyang Xi, Chunxiang Zhang, Chunhui Ma (2019) Preparation of ultrafine-grained GH4169 superalloy by high-pressure torsion and analysis of grain refinement mechanism. Journal of Alloys and Compounds 777:157-161. https://doi.org/10.1016/J.JALLCOM.2018.10.385

[8] Rahmatabadi D, Shahmirzaloo A, Hashemi R (2019) Using digital image correlation for characterizing the elastic and plastic parameters of ultrafine-grained $\mathrm{Al} 1050$ strips fabricated via accumulative roll bonding process. Materials Research Express 6(8):086542. https://doi.org/10.1088/2053-1591/AB18C3

[9] Ensafi M, Faraji G, Abdolvand H (2017) Cyclic extrusion compression angular pressing (CECAP) as a novel severe plastic deformation method for producing bulk ultrafine grained metals. Materials Letters 197(15):12-16. https://doi.org/10.1016/J.MATLET.2017.03.142

[10] Travis L. Brown, Christopher Saldana, Tejas G. Murthy, James B. Mann, Yang Guo, Larry F. Allard, Alexander H. King, W. Dale Compton, Kevin P. Trumble, Srinivasan Chandrasekar (2009) A study of the interactive effects of strain, strain rate and temperature in severe plastic deformation of copper. Acta Materialia 57 (18): 5491-5500. https://doi.org/10.1016/J.ACTAMAT.2009.07.052

[11] W. Moscoso, M. R. Shankar, J. B. Mann, W. D. Compton, S. Chandrasekar (2007) Bulk nanostructured materials by large strain extrusion machining. Journal of Materials Research 22(1):201-205. https://doi.org/10.1557/JMR.2007.0021

[12] Y.Lou, J.S.He, H.Chen, M.Long (2017) Effects of vibration amplitude and relative grain size on the rheological behavior of copper during ultrasonic-assisted microextrusion. The International Journal of Advanced Manufacturing Technology 89(5):2421-2433. https://doi.org/10.1007/S00170-016-9288-7

[13] Jiqiang Zhai, Yanjin Guan, Yi Li, Ya Liu, Jun Lin (2021) Effects of ultrasonic vibration on the deformation behavior of copper in micro-coining. The International Journal of Advanced Manufacturing Technology 114(7): 2357-2370. https://doi.org/10.1007/S00170-021-06983-X

[14]F. Ahmadi, M. Farzin, M. Meratian, S. M. Loeian, M. R. Forouzan (2015) Improvement of ECAP process by imposing ultrasonic vibrations. The International Journal of Advanced Manufacturing Technology, 2015 79(1):503-512. https://doi.org/10.1007/S00170-015-6848-1

[15] Xinhua Zhang, Yuansong Zeng, Dongpo Wang, Ting Wang (2008) Surface hardening effectiveness on aluminium alloy 7075-T651 by ultrasonic shot peening. Aeronautical Manufacturing Technology 13:78-80. https://doi.org/10.3969/j.issn.1671-833X.2008.13.014

[16] Minglong Cheng, Yong Xiao, Kangning Liu, Deyuan Zhang (2019) Investigations on effects of ultrasonic rolling process on surface microstructure of steel. Tool Engineering 2019, 53(7):73-76.

https://doi.org/10.3969/j.issn.1000-7008.2019.07.016

[17] Jianxun Lu, Xiaoyu Wu, Zhaozhi Wu, Zhiyuan Liu, Dengji Guo, Yan Lou, Shuangchen Ruan (2017) microstructure and mechanical properties of ultrafine grained Al-6061 prepared using intermittent ultrasonic assisted equal-channel angular pressing. Journal of Materials Engineering\& Performance 26(10):1-11. https://doi.org/10.1007/S11665-017-2946-6

[18] Bagherzadeh S, Abrinia K, Han Q (2020) Analysis of plastic deformation behavior of ultrafine-grained aluminum processed by the newly developed ultrasonic vibration enhanced ECAP: simulation and experiments. Journal of Manufacturing Processes 50:485-497. https://doi.org/10.1016/J.JMAPRO.2020.01.010

[19] Xiaolong Yin, Wenjun Deng, Yinhui Zou, Jiayang Zhang (2019) Ultrafine grained Al 7075 alloy fabricated by cryogenic temperature large strain extrusion machining combined with aging treatment. Materials Science \& 
Engineering A 762:138106. https://doi.org/ 10.1016/J.MSEA.2019.138106

[20] Pingtian Liu (2017) Finite element simulation of ultrasonic vibration turning and parameter optimization. Tool Engineering 51(1):31-36. https://doi.org/ 10.16567/j.cnki.1000-7008.2017.01.007

[21] Mert Efe, Wilfredo Moscoso, Kevin P. Trumble, W. Dale Compton, Srinivasan Chandrasekar (2012) Mechanics of large strain extrusion machining and application to deformation processing of magnesium alloys Acta Mater. 60 (5) 2031-2042. https://doi.org/10.1016/J.ACTAMAT.2012.01.018

[22] Guo Y, Efe M, Moscoso W, Sagapuram D, Trumble K.P, Chandrasekar S (2011) Deformation field in large-strain extrusion machining and implications for deformation processing. Scripta Materialia 66(5):235-238. https://doi.org/10.1016/J.SCRIPTAMAT.2011.10.045

[23] Yin Xiaolong (2020) Research on fabrication of ultrafine grained Al 7075 alloy via cryogenic temperature extrusion machining. Dissertation, South China University of Technology

[24] Qian Lin, puchu Xie, Jiangbo Hu, Fengguo Zhang, Pei Wang, Yonggang Wang (2021) Numerical simulation on dynamic damage evolution of high pure copper with different grain sizes. Acta Physica Sinica 1-20 https://doi.org/10.7498/aps.70.20210726

[25] G. Dirras, A. Ouarem, H. Couque, J. Gubicza, P. Szommer, O. Brinza (2011) Microstructure and nanohardness distribution in a polycrystalline Zn deformed by high strain rate impact. Materials Characterization 62(5):480-487. https://doi.org/10.1016/J.MATCHAR.2011.03.002

[26] Kang J H, Torizuka S (2007) Dynamic recrystallization by large strain deformation with a high strain rate in an ultralow carbon steel. Scripta Materialia 57(11):1048-1051. https://doi.org/10.1016/J.SCRIPTAMAT.2007.07.039

[27] Song Liu (2020) Evaluation and analysis on uncertainty of measuring metal average grain size by intersection point method. Failure Analysis and Prevention 15(1):6-11 https://doi.org/10.3969/j.issn.1673-6214.2020.01.002

[28] Srinivasan Swaminathan, M.Ravi Shankar, Balkrishna C.Rao, W.Dale Compton, Srinivasan Chandrasekar, Alexander H.King, Kevin P.Trumble (2007) Severe plastic deformation (SPD) and nanostructured materials by machining. Journal of Materials Science 42(5): 1529-1541. https://doi.org/10.1007/S10853-006-0745-9

[29] Deng W J, Li Q, Li B L, et al. (2014) Thermal stability of ultrafine grained aluminium alloy prepared by large strain extrusion machining. Materials Science and Technology 30(7):850-859. https://doi.org/10.1179/1743284713Y.0000000421

[30] Su Qian, Xu Jie, Li Yuqiao, Yoon Jae Ik, Shan Debin, Guo Bin, Kim Hyoung Seop (2018) Microstructural evolution and mechanical properties in superlight $\mathrm{Mg}-\mathrm{Li}$ alloy processed by high pressure torsion. Materials 11(4):598. https://doi.org/10.3390/MA11040598

[31]C. Ye, S. Sergey, D. Lin, Y.L. Liao, G.J. Cheng (2014) Cryogenic ultrahigh strain rate deformation induced hybrid nanotwinned microstructure for high strength and high ductility. Journal of Applied Physics 115(21):213519. https://doi.org/10.1063/1.4881555

[32] Qian Bai, Heng Feng, Li-Kun Si, Ran Pan, Yi-Qi Wang (2019) A Novel Stress Relaxation Modeling for Predicting the Change of Residual Stress During Annealing Heat Treatment. Metallurgical and Materials Transactions A, 50(12):5750-5759. https://doi.org/10.1007/S11661-019-05454-Z

[33] Shigeto Takebayashi, Tomonori Kunieda, Naoki Yoshinaga, Kohsaku Ushioda, Shigenobu Ogata (2010) Comparison of the Dislocation Density in Martensitic Steels Evaluated by Some X-ray Diffraction Methods. ISIJ International, 50(6):875-882. https://doi.org/10.2355/ISIJINTERNATIONAL.50.875 